\title{
A Study on Intuitionistic L-Fuzzy Translation
}

\author{
P.Pandiammal, PhD. \\ Department of Mathematics, PSNACET, \\ Dindigul, Tamil Nadu, India
}

\author{
R.Natarajan, PhD. \\ HOD, Department of Mathematics, \\ Alagappa University, \\ Karaikudi-630 003, Tamil Nadu, India
}

\begin{abstract}
This paper contains some definitions and results in intuitionistic L-fuzzy translation of Intuitionistic

L-fuzzy Msubgroup of a M-group, which are required in the sequel. Some properties of homomorphism and anti-homomorphism of Intuitionistic L-fuzzy translation are also established.
\end{abstract}

\section{AMS Subject Classification: 20M12, 03F55, 08A72}

\section{Keywords:}

L-fuzzy set, L-fuzzy M-subgroup, Homomorphism, Anti-homomorphism, Anti L-fuzzy M-subgroup, intuitionistic Lfuzzy M-subgroups, intuitionistic L-fuzzy translation.

\section{INTRODUCTION:}

The notion of fuzzy sets was introduced by L.A. Zadeh [9]. Fuzzy set theory has been developed in many directions by many researchers and has evoked great interest among mathematicians working in different fields of mathematics, such as topological spaces, functional analysis, loop, group, ring, near ring, vector spaces, automation. In 1971, Rosenfield [1] introduced the concept of fuzzy subgroup. Motivated by this, many mathematicians started to review various concepts and theorems of abstract algebra in the broader frame work of fuzzy settings. In [2], Biswas introduced the concept of anti-fuzzy subgroups of groups. Palaniappan. N and Muthuraj, [6] defined the homomorphism, anti-homomorphism of a fuzzy and an anti-fuzzy subgroups. Pandiammal. P, Natarajan. R, and Palaniappan. N, [8] defined the homomorphism, anti-homomorphism of an anti L-fuzzy M-subgroup. In this paper we define a new algebraic structure of intuitionistic L-fuzzy translation of intuitionistic L-fuzzy M-subgroup of a Mgroup and study some their related properties.

\section{PRELIMINARIES:}

2.1 Definition: Let $G$ be a M-group. A L-fuzzy subset A of G is said to be anti L-fuzzy M-subgroup (ALFMSG) of $G$ if its satisfies the following axioms:

$$
\begin{aligned}
& \text { (i) } \mu_{\mathrm{A}}(\mathrm{mxy}) \leq \mu_{\mathrm{A}}(\mathrm{x}) \vee \mu_{\mathrm{A}}(\mathrm{y}), \\
& \text { (ii) } \mu_{\mathrm{A}}\left(\mathrm{x}^{-1}\right) \leq \mu_{\mathrm{A}}(\mathrm{x}) \text {, for all } \mathrm{x} \text { and } \mathrm{y} \text { in } \mathrm{G} \text {. }
\end{aligned}
$$

2.2 Definition: Let $(\mathrm{G}, \cdot)$ be a

M-group. An intuitionistic L-fuzzy subset A of $\mathrm{G}$ is said to be an intuitionistic L-fuzzy M-subgroup (ILFMSG) of $G$ if the following conditions are satisfied:
(i) $\mu_{\mathrm{A}}(\mathrm{mxy}) \geq \mu_{\mathrm{A}}(\mathrm{x}) \wedge \mu_{\mathrm{A}}(\mathrm{y})$,
(ii) $\mu_{\mathrm{A}}\left(\mathrm{x}^{-1}\right) \geq \mu_{\mathrm{A}}(\mathrm{x})$,
(iii) $v_{\mathrm{A}}(\mathrm{mxy}) \leq v_{\mathrm{A}}(\mathrm{x}) \vee v_{\mathrm{A}}(\mathrm{y})$,

$$
\text { (iv) } v_{\mathrm{A}}\left(\mathrm{x}^{-1}\right) \leq v_{\mathrm{A}}(\mathrm{x}) \text {, for all } \mathrm{x} \text { and } \mathrm{y} \text { in } \mathrm{G} \text {. }
$$

2.3 Definition: Let $A$ be an intuitionistic L-fuzzy subset of $\mathrm{X}$ and $\alpha$ and $\beta$ in $\left[0,1-\operatorname{Sup}\left\{\mu_{\mathrm{A}}(\mathrm{x})+\right.\right.$ $v_{\mathrm{A}}(\mathrm{x}): \mathrm{x} \in \mathrm{X}$, $\left.\left.0<\mu_{\mathrm{A}}(\mathrm{x})+v_{\mathrm{A}}(\mathrm{x})<1\right\}\right]$. Then $\mathrm{T}=$ $T_{(\alpha, \beta)}^{A}$ is called an intuitionistic L-fuzzy translation of A if $\mu_{\mathrm{T}}(\mathrm{x})=\mu_{\alpha}^{A}(\mathrm{x})=\mu_{\mathrm{A}}(\mathrm{x})+\alpha, v_{\mathrm{T}}(\mathrm{x})=v_{\beta}^{A}(\mathrm{x})=v_{\mathrm{A}}(\mathrm{x})+$ $\beta, \alpha+\beta \leq 1-\operatorname{Sup}\left\{\mu_{\mathrm{A}}(\mathrm{x})+v_{\mathrm{A}}(\mathrm{x}): \mathrm{x} \in \mathrm{X}, \quad 0<\mu_{\mathrm{A}}(\mathrm{x})\right.$ $\left.+v_{\mathrm{A}}(\mathrm{x})<1\right\}$, for all $\mathrm{x}$ in $\mathrm{X}$.

Remark 2.4 : When $\mu \mathrm{A}(\mathrm{x})+v \mathrm{~A}(\mathrm{x})=1$, i.e. when $v \mathrm{~A}(\mathrm{x})=1-\mu \mathrm{A}(\mathrm{x})=\mu \mathrm{Ac}(\mathrm{x})$.

Then A is called fuzzy set.

Example 2.5: Let $X=\{1, \omega, \omega 2\}$. Let $A=\{<1,0.3,0.4$ $>,\langle\omega, 0.1,0.25>$,

$<\omega 2,0.5,0.3>\}$ be an IFS of X. Then $\quad[0,1-\operatorname{Sup}\{$ $\mu \mathrm{A}(\mathrm{x})+v \mathrm{~A}(\mathrm{x}): \mathrm{x}$ in $\mathrm{X}$,

$0<\mu \mathrm{A}(\mathrm{x})+v \mathrm{~A}(\mathrm{x})<1\}]=[0,0.2]$. Take $\alpha=0.1$ and $\beta=0.2$.Then ILFT of the

IFS A is given by $\mathrm{T}=\{\langle 1,0.16,0.18\rangle,\langle\omega, 0.12,0.15$ $>,\langle\omega 2,0.11,0.16>\}$

\section{PROPERTIES OF INTUITIONISTIC L-FUZZY TRANSLATION:}

3.1 Theorem: If $\mathrm{T}$ is an intuitionistic L-fuzzy translation of an intuitionistic L-fuzzy M-subgroup A of a M-group $\mathrm{G}$, then $\mu_{\mathrm{T}}\left(\mathrm{x}^{-1}\right)=\mu_{\mathrm{T}}(\mathrm{x})$ and $\nu_{\mathrm{T}}\left(\mathrm{x}^{-1}\right)=$ $\nu_{\mathrm{T}}(\mathrm{x}), \mu_{\mathrm{T}}(\mathrm{x}) \leq \mu_{\mathrm{T}}(\mathrm{e})$ and $\nu_{\mathrm{T}}(\mathrm{x}) \geq \nu_{\mathrm{T}}(\mathrm{e})$, for all $\mathrm{x}$ and $\mathrm{e}$ in $\mathrm{G}$.

Proof: Let $\mathrm{x}$ and e be elements of G.

$$
\text { Now, } \quad \begin{aligned}
\mu_{\mathrm{T}}(\mathrm{x}) \quad & =\mu_{\mathrm{A}}(\mathrm{x})+\alpha \\
& =\mu_{\mathrm{A}}\left(\left(\mathrm{x}^{-1}\right)^{-1}\right)+\alpha \\
& \geq \mu_{\mathrm{A}}\left(\mathrm{x}^{-1}\right)+\alpha=\mu_{\mathrm{T}}(\mathrm{x}) .
\end{aligned}
$$

Therefore, $\mu_{\mathrm{T}}(\mathrm{x})=\mu_{\mathrm{T}}\left(\mathrm{x}^{-1}\right)$, for $\mathrm{x}$ in $\mathrm{G}$.

And, $\quad v_{\mathrm{T}}(\mathrm{x})=v_{\mathrm{A}}(\mathrm{x})+\beta$

$$
\begin{aligned}
& =v_{\mathrm{A}}\left(\left(\mathrm{x}^{-1}\right)^{-1}\right. \\
& =\mathrm{v}_{\mathrm{T}}(\mathrm{x}) .
\end{aligned}
$$

Therefore, $v_{\mathrm{T}}(\mathrm{x})=v_{\mathrm{T}}\left(\mathrm{x}^{-1}\right)$, for $\mathrm{x}$ in $\mathrm{G}$.

Now,

$$
\begin{aligned}
\mu_{\mathrm{T}}(\mathrm{e})= & \mu_{\mathrm{A}}(\mathrm{e})+\alpha \\
& =\mu_{\mathrm{A}}\left(\mathrm{xx}^{-1}\right)+\alpha \\
& \geq\left\{\mu_{\mathrm{A}}(\mathrm{x}) \wedge \mu_{\mathrm{A}}\left(\mathrm{x}^{-1}\right)\right\}+\alpha
\end{aligned}
$$


,for $\mathrm{x}$ in $\mathrm{G}$.

$$
=\mu_{\mathrm{A}}(\mathrm{x})+\alpha=\mu_{\mathrm{T}}(\mathrm{x}) \text {. Therefore, } \mu_{\mathrm{T}}(\mathrm{e}) \geq \mu_{\mathrm{T}}(\mathrm{x})
$$

$$
\text { And } \quad \begin{aligned}
& v_{\mathrm{T}}(\mathrm{e})=v_{\mathrm{A}}(\mathrm{e})+\beta \\
&= v_{\mathrm{A}}\left(\mathrm{xx}^{-1}\right)+\beta \\
& \leq\left\{v_{\mathrm{A}}(\mathrm{x}) \vee v_{\mathrm{A}}\left(\mathrm{x}^{-1}\right)\right\}+\beta \\
&= v_{\mathrm{A}}(\mathrm{x})+\beta=v_{\mathrm{T}}(\mathrm{x}) .
\end{aligned}
$$

Therefore, $v_{\mathrm{T}}(\mathrm{e}) \leq \mathrm{v}_{\mathrm{T}}(\mathrm{x})$, for $\mathrm{x}$ in $\mathrm{G}$.

3.2 Theorem: If $\mathrm{T}$ is an intuitionistic L-fuzzy translation of an intuitionistic L-fuzzy M-subgroup A of a M-group G, then

(i) $\mu_{\mathrm{T}}\left(\mathrm{xy}^{-1}\right)=\mu_{\mathrm{T}}(\mathrm{e})$ implies $\mu_{\mathrm{T}}(\mathrm{x})=\mu_{\mathrm{T}}(\mathrm{y})$,

(ii) $\nu_{\mathrm{T}}\left(\mathrm{xy}^{-1}\right)=v_{\mathrm{T}}(\mathrm{e})$ implies $v_{\mathrm{T}}(\mathrm{x})=v_{\mathrm{T}}(\mathrm{y})$, for all $\mathrm{x}, \mathrm{y}$ and $\mathrm{e}$ in $\mathrm{G}$.

Proof: Let $x$, y and e be elements of G.

Now,

$$
\begin{aligned}
\mu_{\mathrm{T}}(\mathrm{x})=\mu_{\mathrm{A}}(\mathrm{x})+\alpha \\
=\mu_{\mathrm{A}}\left(\mathrm{xy}^{-1} \mathrm{y}\right)+\alpha \\
\geq\left(\mu_{\mathrm{A}}\left(\mathrm{xy}^{-1}\right)+\alpha\right) \wedge\left(\mu_{\mathrm{A}}(\mathrm{y})+\alpha\right) \\
=\mu_{\mathrm{T}}\left(\mathrm{xy}^{-1}\right) \wedge \mu_{\mathrm{T}}(\mathrm{y}) \\
=\mu_{\mathrm{T}}(\mathrm{e}) \wedge \mu_{\mathrm{T}}(\mathrm{y})=\mu_{\mathrm{T}}(\mathrm{y}) \\
=\mu_{\mathrm{A}}(\mathrm{y})+\alpha=\mu_{\mathrm{A}}\left(\mathrm{yx}^{-1} \mathrm{x}\right)+\alpha \\
\geq\left\{\mu_{\mathrm{A}}\left(\mathrm{yx}^{-1}\right) \wedge \mu_{\mathrm{A}}(\mathrm{x})\right\}+\alpha \\
=\left(\mu_{\mathrm{A}}\left(\mathrm{yx}^{-1}\right)+\alpha \wedge\left(\mu_{\mathrm{A}}(\mathrm{x})+\alpha\right)\right. \\
=\mu_{\mathrm{T}}\left(\mathrm{yx}^{-1}\right) \wedge \mu_{\mathrm{T}}(\mathrm{x}) \\
=\mu_{\mathrm{T}}(\mathrm{e}) \wedge \mu_{\mathrm{T}}(\mathrm{x})=\mu_{\mathrm{T}}(\mathrm{x}) .
\end{aligned}
$$

Therefore, $\mu_{\mathrm{T}}(\mathrm{x})=\mu_{\mathrm{T}}(\mathrm{y})$, for all $\mathrm{x} \& \mathrm{y}$ in $\mathrm{G}$.

Similarly, $v_{\mathrm{T}}(\mathrm{x})=v_{\mathrm{T}}(\mathrm{y})$, for all $\mathrm{x} \& \mathrm{y}$ in $\mathrm{G}$.

3.3 Theorem: If $\mathrm{T}$ is an intuitionistic

L-fuzzy translation of an intuitionistic L-fuzzy M-subgroup A of a M-group $\mathrm{G}$, then $\mathrm{T}$ is an intuitionistic L-fuzzy M-subgroup of a M-group $\mathrm{G}$, for all $\mathrm{x}$ and $\mathrm{y}$ in $\mathrm{G}$.

Proof: Assume that $\mathrm{T}$ is an intuitionistic

L-fuzzy translation of an intuitionistic M-group $\mathrm{G}$. Let $\mathrm{x}$ and $\mathrm{y}$ in $\mathrm{G}$.

We have, $\mu_{\mathrm{T}}\left(\mathrm{mxy}^{-1}\right)=\mu_{\mathrm{A}}\left(\mathrm{mxy}^{-1}\right)+\alpha$

$$
\begin{aligned}
& \geq\left\{\mu_{\mathrm{A}}(\mathrm{x}) \wedge \mu_{\mathrm{A}}\left(\mathrm{y}^{-1}\right)\right\}+\alpha=\left\{\mu_{\mathrm{A}}(\mathrm{x}) \wedge\right. \\
& \left.\mu_{\mathrm{A}}(\mathrm{y})\right\}+\alpha=\mu_{\mathrm{T}}(\mathrm{x}) \wedge \mu_{\mathrm{T}}(\mathrm{y}) .
\end{aligned}
$$

Therefore, $\mu_{\mathrm{T}}\left(\mathrm{mxy}^{-1}\right) \geq \mu_{\mathrm{T}}(\mathrm{x}) \wedge \mu_{\mathrm{T}}(\mathrm{y})$, for all $\mathrm{x}$ and $\mathrm{y}$ in $\mathrm{G}$.

$$
\begin{aligned}
\text { And, } v_{\mathrm{T}}\left(\mathrm{mxy}^{-1}\right)=v_{\mathrm{A}} & \left(\mathrm{mxy}^{-1}\right)+\beta \\
& \leq\left\{v_{\mathrm{A}}(\mathrm{x}) \vee v_{\mathrm{A}}\left(\mathrm{y}^{-1}\right)\right\}+\beta \\
& =\left\{v_{\mathrm{A}}(\mathrm{x}) \vee v_{\mathrm{A}}(\mathrm{y})\right\}+\beta \\
& v_{\mathrm{T}}(\mathrm{x}) \vee v_{\mathrm{T}}(\mathrm{y}) .
\end{aligned}
$$

Therefore, $v_{\mathrm{T}}\left(\mathrm{mxy}^{-1}\right) \leq v_{\mathrm{T}}(\mathrm{x}) \vee v_{\mathrm{T}}(\mathrm{y})$, for all $\mathrm{x}$ and $\mathrm{y}$ in $\mathrm{G}$.

Hence $\mathrm{T}$ is an intuitionistic L-fuzzy

M-subgroup of a Mgroup $\mathrm{G}$.

3.4 Theorem: If $\mathrm{T}$ is an intuitionistic

L-fuzzy translation of an intuitionistic L-fuzzy M-subgroup A of a M-group G, then $H=\left\{x \in G: \mu_{T}(x)=\mu_{T}(e)\right.$ and $\left.\nu_{T}(x)=\nu_{T}(e)\right\}$ is a Msubgroup of $\mathrm{G}$.

Proof: Let $\mathrm{x}, \mathrm{y}$ and e be elements of $\mathrm{G}$.

Given $\mathrm{H}=\left\{\mathrm{x} \in \mathrm{G}: \mu_{\mathrm{T}}(\mathrm{x})=\mu_{\mathrm{T}}(\mathrm{e})\right.$ and $\left.\nu_{\mathrm{T}}(\mathrm{x})=v_{\mathrm{T}}(\mathrm{e})\right\}$.

Now, $\quad \mu_{\mathrm{T}}\left(\mathrm{x}^{-1}\right)=\mu_{\mathrm{T}}(\mathrm{x})=\mu_{\mathrm{T}}(\mathrm{e})$ and $\quad v_{\mathrm{T}}\left(\mathrm{x}^{-1}\right)=v_{\mathrm{T}}(\mathrm{x})=$ $v_{\mathrm{T}}(\mathrm{e})$.

Therefore, $\mu_{\mathrm{T}}\left(\mathrm{x}^{-1}\right)=\mu_{\mathrm{T}}(\mathrm{e})$ and $v_{\mathrm{T}}\left(\mathrm{x}^{-1}\right)=$ $v_{\mathrm{T}}(\mathrm{e})$. Therefore, $\mathrm{x}^{-1} \in \mathrm{H}$.

Now, $\mu_{\mathrm{T}}\left(\mathrm{xy}^{-1}\right) \geq \mu_{\mathrm{T}}(\mathrm{x}) \wedge \mu_{\mathrm{T}}(\mathrm{y})$

$$
\begin{aligned}
& =\mu_{\mathrm{T}}(\mathrm{e}) \wedge \mu_{\mathrm{T}}(\mathrm{e}) \\
& =\mu_{\mathrm{T}}(\mathrm{e}) \text {, } \\
& \text { and } \quad \mu_{\mathrm{T}}(\mathrm{e}) \quad=\mu_{\mathrm{T}}\left(\left(\mathrm{xy}^{-1}\right)\left(\mathrm{xy}^{-1}\right)^{-1}\right) \\
& \geq \mu_{\mathrm{T}}\left(\mathrm{xy}^{-1}\right) \wedge \mu_{\mathrm{T}}\left(\mathrm{xy}^{-1}\right) \\
& =\mu_{\mathrm{T}}\left(\mathrm{xy}^{-1}\right) \text {. }
\end{aligned}
$$

Therefore, $\mu_{\mathrm{T}}(\mathrm{e})=\mu_{\mathrm{T}}\left(\mathrm{xy}^{-1}\right)$, for all $\mathrm{x}$ and $\mathrm{y}$ in $\mathrm{G}$.

Similarly, $v_{\mathrm{A}}(\mathrm{e})=v_{\mathrm{A}}\left(\mathrm{xy}^{-1}\right)$, for all $\mathrm{x} \& \mathrm{y}$ in $\mathrm{G}$.

Therefore, $x y^{-1}$ in $\mathrm{H}$. Hence $\mathrm{H}$ is a M-subgroup of G.

3.5 Theorem: Let $\mathrm{T}$ be an intuitionistic L-fuzzy translation of an intuitionistic L-fuzzy M-subgroup A of a M-group G. If $\mu_{\mathrm{T}}\left(\mathrm{xy}^{-1}\right)=1$, then $\mu_{\mathrm{T}}(\mathrm{x})=\mu_{\mathrm{T}}(\mathrm{y})$ and if $v_{\mathrm{T}}\left(\mathrm{xy}^{-1}\right)=0$, then $v_{\mathrm{T}}(\mathrm{x})=v_{\mathrm{T}}(\mathrm{y})$.

Proof: Let $\mathrm{x}$ and $\mathrm{y}$ be elements of $\mathrm{G}$.

Now, $\mu_{\mathrm{T}}(\mathrm{x})=\mu_{\mathrm{T}}\left(\mathrm{xy}^{-1} \mathrm{y}\right)$

$$
\begin{aligned}
& \geq \mu_{\mathrm{T}}\left(\mathrm{xy}^{-1}\right) \wedge \mu_{\mathrm{T}}(\mathrm{y}) \\
& =1 \wedge \mu_{\mathrm{T}}(\mathrm{y}) \\
& =\mu_{\mathrm{T}}(\mathrm{y})=\mu_{\mathrm{T}}\left(\mathrm{y}^{-1}\right) \\
& =\mu_{\mathrm{T}}\left(\mathrm{x}^{-1} \mathrm{xy}^{-1}\right) \\
& \geq \mu_{\mathrm{T}}\left(\mathrm{x}^{-1}\right) \wedge \mu_{\mathrm{T}}\left(\mathrm{xy}^{-1}\right) \\
& =\mu_{\mathrm{T}}(\mathrm{x}) \wedge \mu_{\mathrm{T}}\left(\mathrm{xy}^{-1}\right)=\mu_{\mathrm{T}}(\mathrm{x}) .
\end{aligned}
$$

Therefore, $\mu_{\mathrm{T}}(\mathrm{x})=\mu_{\mathrm{T}}(\mathrm{y})$, for all $\mathrm{x} \& \mathrm{y}$ in $\mathrm{G}$.

$$
\text { Now, } \quad \begin{aligned}
v_{\mathrm{T}}(\mathrm{x})= & v_{\mathrm{T}}\left(\mathrm{xy}^{-1} \mathrm{y}\right) \leq v_{\mathrm{T}}(\mathrm{y}) \\
& =v_{\mathrm{T}}\left(\mathrm{y}^{-1}\right) \\
& =v_{\mathrm{T}}\left(\mathrm{x}^{-1} \mathrm{xy}^{-1}\right) \\
& \leq v_{\mathrm{T}}\left(\mathrm{x}^{-1}\right) \vee v_{\mathrm{T}}\left(\mathrm{xy}^{-1}\right) \\
& =v_{\mathrm{T}}(\mathrm{x}) \vee v_{\mathrm{T}}\left(\mathrm{xy}^{-1}\right) \\
& =v_{\mathrm{T}}(\mathrm{x}) \vee 0=v_{\mathrm{T}}(\mathrm{x})
\end{aligned}
$$

Therefore, $v_{\mathrm{T}}(\mathrm{x})=\mathrm{v}_{\mathrm{T}}(\mathrm{y})$, for all $\mathrm{x} \& \mathrm{y}$ in $\mathrm{G}$.

3.6 Theorem: Let $\mathrm{G}$ be a $\mathrm{M}$-group. If $\mathrm{T}$ is an intuitionistic L-fuzzy translation of an intuitionistic L-fuzzy Msubgroup $A$ of $\mathrm{G}$, then $\mu_{\mathrm{T}}(\mathrm{xy})=\mu_{\mathrm{T}}(\mathrm{x}) \wedge \mu_{\mathrm{T}}(\mathrm{y})$ and $v_{\mathrm{T}}(\mathrm{xy})=\nu_{\mathrm{T}}(\mathrm{x}) \vee v_{\mathrm{T}}(\mathrm{y})$, for each $\mathrm{x}$ and $\mathrm{y}$ in $\mathrm{G}$ with $\mu_{\mathrm{T}}(\mathrm{x}) \neq$ $\mu_{\mathrm{T}}(\mathrm{y})$ and $\quad v_{\mathrm{T}}(\mathrm{x}) \neq v_{\mathrm{T}}(\mathrm{y})$.

Proof: Let $\mathrm{x}$ and $\mathrm{y}$ be elements of $\mathrm{G}$.

Assume that $\mu_{\mathrm{T}}(\mathrm{x})>\mu_{\mathrm{T}}(\mathrm{y})$ and $\quad \nu_{\mathrm{T}}(\mathrm{x})<v_{\mathrm{T}}(\mathrm{y})$. 
Then,

$$
\begin{aligned}
\mu_{\mathrm{T}}(\mathrm{y})= & \mu_{\mathrm{T}}\left(\mathrm{x}^{-1} \mathrm{xy}\right) \\
& \geq \mu_{\mathrm{T}}\left(\mathrm{x}^{-1}\right) \wedge \mu_{\mathrm{T}}(\mathrm{xy})=\mu_{\mathrm{T}}(\mathrm{x}) \wedge \mu_{\mathrm{T}}(\mathrm{xy}) \\
& =\mu_{\mathrm{T}}(\mathrm{xy}) \\
& \geq \mu_{\mathrm{T}}(\mathrm{x}) \wedge \mu_{\mathrm{T}}(\mathrm{y})=\mu_{\mathrm{T}}(\mathrm{y}) .
\end{aligned}
$$

Therefore, $\mu_{\mathrm{T}}(\mathrm{xy})=\mu_{\mathrm{T}}(\mathrm{y})=\mu_{\mathrm{T}}(\mathrm{x}) \wedge \mu_{\mathrm{T}}(\mathrm{y})$, for all $\mathrm{x}$ and $\mathrm{y}$ in $\mathrm{G}$.

Then, $\quad v_{\mathrm{T}}(\mathrm{y})=v_{\mathrm{T}}\left(\mathrm{x}^{-1} \mathrm{xy}\right)$

$$
\begin{aligned}
& \leq v_{\mathrm{T}}\left(\mathrm{x}^{-1}\right) \vee v_{\mathrm{T}}(\mathrm{xy}) \\
& =v_{\mathrm{T}}(\mathrm{xy}) \\
& \leq v_{\mathrm{T}}(\mathrm{x}) \vee v_{\mathrm{T}}(\mathrm{y})=v_{\mathrm{T}}(\mathrm{y}) .
\end{aligned}
$$

Therefore, $v_{\mathrm{T}}(\mathrm{xy})=v_{\mathrm{T}}(\mathrm{y})=$ and $\mathrm{y}$ in $\mathrm{G}$.

$v_{\mathrm{T}}(\mathrm{x}) \vee v_{\mathrm{T}}(\mathrm{y})$, for all $\mathrm{x}$

3.7 Theorem: Let $(\mathrm{G}, \bullet)$ and $\left(\mathrm{G}^{\prime}, \bullet\right)$ be any two M-groups. If $\mathrm{f}$ : $\mathrm{G} \rightarrow \mathrm{G}^{\prime}$ is a homomorphism, then the homomorphic image (preimage) of an intuitionistic L-fuzzy translation of an intuitionistic L-fuzzy M-subgroup A of a M-group $\mathrm{G}$ is an intuitionistic Lfuzzy M-subgroup of a M-group $\mathrm{G}^{\prime}$.

Proof: Let $(G, \bullet)$ and $\left(G^{\prime}, \bullet\right)$ be any two M-groups and $f: G \rightarrow G^{\prime}$ be a homomorphism. That is $f(x y)=f(x) f(y), f(m x y)=m f(x)$ $\mathrm{f}(\mathrm{y})$, for all $\mathrm{x}$ and $\mathrm{y}$ in $\mathrm{G}$ and $\mathrm{m}$ in $\mathrm{M}$.

Let $\mathrm{V}=\mathrm{f}\left(T_{(\alpha, \beta)}^{A}\right)$, where $T_{(\alpha, \beta)}^{A}$ is an intuitionistic L-fuzzy translation of an intuitionistic L-fuzzy M-subgroup A of a Mgroup $\mathrm{G}$.

We have to prove that $\mathrm{V}$ is an intuitionistic L-fuzzy M-subgroup of a M-group $\mathrm{G}^{\prime}$.

Now, for $\mathrm{f}(\mathrm{x})$ and $\mathrm{f}(\mathrm{y})$ in $\mathrm{G}^{\prime}$, we have

$$
\begin{aligned}
\mu_{\mathrm{V}}\left[\operatorname{mf}(\mathrm{x})\left(\mathrm{f}(\mathrm{y})^{-1}\right)\right]= & \mu_{\mathrm{V}}\left[\operatorname{mf}(\mathrm{x}) \mathrm{f}\left(\mathrm{y}^{-1}\right)\right] \\
& =\mu_{\mathrm{V}}\left[\mathrm{f}\left(\mathrm{mx} \mathrm{y}^{-1}\right)\right] \\
& \geq \mu_{\alpha}^{A}\left(\mathrm{mxy}^{-1}\right) \quad=\mu_{\mathrm{A}}\left(\mathrm{mx} \mathrm{y}^{-1}\right)+ \\
& \alpha \\
& \geq\left\{\mu_{\mathrm{A}}(\mathrm{x}) \wedge \mu_{\mathrm{A}}\left(\mathrm{y}^{-1}\right)\right\}+\alpha \geq\left\{\mu_{\mathrm{A}}(\mathrm{x}) \wedge \mu_{\mathrm{A}}(\mathrm{y})\right\} \\
& +\alpha \\
& ) \wedge\left(\mu_{\mathrm{A}}(\mathrm{y})+\alpha\right)=\mu_{\alpha}^{A}(\mathrm{x}) \wedge
\end{aligned}
$$

which implies that $\mu_{\mathrm{V}}\left[\operatorname{mf}(\mathrm{x})\left(\mathrm{f}(\mathrm{y})^{-1}\right)\right] \geq \mu_{\mathrm{V}}(\mathrm{f}(\mathrm{x})) \wedge \mu_{\mathrm{V}}(\mathrm{f}(\mathrm{y}))$, for all $\mathrm{f}(\mathrm{x})$ and $\mathrm{f}(\mathrm{y})$ in $\mathrm{G}^{\prime}$.

Similarly, $\mathrm{V}$ is an intuitionistic L-fuzzy M-subgroup of a Mgroup $\mathrm{G}^{\mathrm{l}}$.

Hence the homomorphic image of an intuitionistic L-fuzzy translation of A of $\mathrm{G}$ is an intuitionistic L-fuzzy subgroup of a M-group $\mathrm{G}^{\prime}$.

3.8 Theorem: Let $(G, \bullet)$ and $\left(G^{\prime}, \bullet\right)$ be any two M-groups. If $f$ : $\mathrm{G} \rightarrow \mathrm{G}^{\prime}$ is an anti-homomorphism, then the anti-homomorphic image (pre-image) of an intuitionistic L-fuzzy translation of an intuitionistic L-fuzzy normal

Msubgroup A of a M-group $\mathrm{G}$ is an intuitionistic L-fuzzy normal M-subgroup of a M-group $\mathrm{G}^{\prime}$.

Proof: Let $(G, \bullet)$ and $\left(G^{\prime}, \bullet\right)$ be any two M-groups and $f: G \rightarrow G^{\prime}$ be an anti-homomorphism.

That is $f(x y)=f(x) f(y), f(m x y)=m f(x) f(y)$, for all $x$ and $y$ in $G$ and $\mathrm{m}$ in $\mathrm{M}$.
Let $\mathrm{V}=\mathrm{f}\left(T_{(\alpha, \beta)}^{A}\right)$, where $T_{(\alpha, \beta)}^{A}$ is an intuitionistic Lfuzzy translation of an intuitionistic L-fuzzy normal M-subgroup A of a M-group G.

We have to prove that $\mathrm{V}$ is an intuitionistic L-fuzzy normal M-subgroup of a M-group $G^{\prime}$.

Now, for $f(x)$ and $f(y)$ in $G^{\prime}$,clearly $V$ is an intuitionistic L-fuzzy M-subgroup of a M-group $\mathrm{G}^{\prime}$. We have, $\mu_{\mathrm{V}}(\operatorname{mf}(\mathrm{x}) \mathrm{f}(\mathrm{y}))=\mu_{\mathrm{V}}(\mathrm{f}(\operatorname{myx}))$

$$
\begin{aligned}
& \geq \mu_{\mathrm{T}}(\operatorname{myx}) \\
& =\mu_{\mathrm{A}}(\operatorname{myx})+\alpha \\
& =\mu_{\mathrm{A}}(\operatorname{mxy})+\alpha \\
& =\mu_{\mathrm{T}}(\operatorname{mxy}) \\
& \leq \mu_{\mathrm{V}}(\mathrm{f}(\mathrm{mxy})) \\
& =\mu_{\mathrm{V}}(\operatorname{mf}(\mathrm{y}) \mathrm{f}(\mathrm{x}))
\end{aligned}
$$

which implies that $\mu_{\mathrm{V}}(\mathrm{mf}(\mathrm{x}) \mathrm{f}(\mathrm{y}))$ $f(x))$, for $f(x)$ and $f(y)$ in $G^{\prime}$.

$$
=\mu_{\mathrm{V}}(\operatorname{mf}(\mathrm{y})
$$

And, $v_{\mathrm{V}}(\operatorname{mf}(\mathrm{x}) \mathrm{f}(\mathrm{y}))=v_{\mathrm{V}}(\mathrm{f}(\operatorname{myx}))$

$$
\begin{aligned}
& \leq v_{\mathrm{T}}(\operatorname{myx}) \\
& =v_{\mathrm{A}}(\mathrm{myx})+\alpha \\
& =v_{\mathrm{A}}(\mathrm{mxy})+\alpha \\
& =v_{\mathrm{T}}(\mathrm{mxy}) \\
& \geq v_{\mathrm{V}}(\mathrm{f}(\mathrm{mxy})) \\
& =v_{\mathrm{V}}(\operatorname{mf}(\mathrm{y}) \mathrm{f}(\mathrm{x}))
\end{aligned}
$$

which implies that $v_{\mathrm{V}}(\operatorname{mf}(\mathrm{x}) \mathrm{f}(\mathrm{y}))=$ $f(x))$, for $f(x)$ and $f(y)$ in $G^{\prime}$.

$v_{\mathrm{V}}(\operatorname{mf}(\mathrm{y})$

Therefore, $\mathrm{V}$ is an intuitionistic L-fuzzy normal Msubgroup of a M-group $\mathrm{G}^{\prime}$.

Hence the anti-homomorphic image of an intuitionistic Lfuzzy translation of A of a M-group $\mathrm{G}$ is an intuitionistic L-fuzzy normal M-subgroup of a M-group $\mathrm{G}^{\prime}$.

\section{CONCLUSION}

In this paper, we define a new algebraic structure of Intuitionistic L-fuzzy translation and Homomorphism and anti-homomorphism of Intuitionistic L-fuzzy Translation, we wish to define Level subset of Intuitionistic L-fuzzy Translatin and other some L-fuzzy Translation are in progress.

\section{REFERENCES}

[1] K. Atanassov "Intuitionistic fuzzy sets", Fuzzy Sets and Systems, 20(1), (1986), 87-96.

[2] K. Atanassov, S. Stoeva, "Intuitionistic fuzzy sets on interval and fuzzy Mathematics" Proceeding of Polish Symposium Poznan, August(1983), pp.23-26.

[3] B. Banerjee and D.K. Basnet, "Intuitionistic fuzzy subrings and ideals , J.of Fuzzy Mathematics, Vol.11, No. 1, (2003), 139-155.

[4] J.A. Goguen, L-fuzzy sets, J. Math. Anal. Appl.18(1967),145-179. 
[5] W.B.V. Kandasamy, "Smrandache fuzzy algebra" American Research Press, (2003), pp. 151-154.

[6] Mohamed Asaad, Groups and Fuzzy Subgroups, Fuzzy Sets and Systems 39(1991)323-328.

[7] Kul Hur and Youn Jang, "The lattice of intuitionistic fuzzy congruences", International Mathematics Forum , No. 5 , (2006), 211-236

[8] N. Kuroki, "On fuzzy ideals and fuzzy bi-ideals in semigroups" Fuzzy Sets and Systems, 5, (1982), 203215.

[9] S.K. Majumder , S.K. Sardar,"Fuzzy magnified translation on groups" Journal of Mathematics, North Bengal University , 1(2), (2008), 117- 124.

[10] S.K. Sardar, M. Mandal and S.K. Majumder, 2011, "On intuitionistic fuzzy magnified translation in semigroup", arXiv:1101.3699Vi [math.GM] 18 Jan 2011

[11] P.K.Sharma., "Intuitionistic fuzzy groups", International Journal of Data Warehousing \& Mining (IIJDWM), Vol. 1 , Issue 1 ,(2011), 86-94
[12] P.K.Sharma., "On Intuitionistic fuzzy magnified Translation in groups", International Journal of Mathematical Sciences and Applications , ( to appear )

[13] P.K.Sharma and Vandana Bansal , "Anti homomorphism of Intuitionistic fuzzy magnified Translation in groups", International Journal of Mathematical Sciences and Applications, ( to appear )

[14] V. Veeramani, K. Arjunan, N. Palaniappan, “ Some properties of Intuitionistic fuzzy normal subrings ," Applied Mathematical Sciences, Vol.4, no. 43, (2010) , 2119-2124

[15] L.A. Zadeh, "Fuzzy sets" Information and Control,8, (1965), 338-353 